\title{
Influence of porosity on the fatigue behaviour of additively fabricated TA6V alloys
}

\author{
Viet-Duc Le ${ }^{1,{ }^{*}}$, Etienne Pessard ${ }^{1}$, Franck Morel $^{1}$, François Edy $^{2}$ \\ ${ }^{1}$ LAMPA, Arts et métiers ParisTech, Centre d'Angers, France \\ ${ }^{2}$ IRT Jules Verne, Bouguenais, France
}

\begin{abstract}
This work is focused on the influence of porosity when dealing with the fatigue behaviour of the TA6V alloys fabricated by the selective laser melting (SLM) process. The presence of porosity is one of the major issue facing additive manufacturing (AM) of metallic components subjected to fatigue loading. In order to study the effect of porosity on the fatigue behaviour, a vast experimental campaign has been undertaken. These materials are fabricated by the SLM process with different building directions (horizontal, vertical and diagonal) thanks to which specimen batches with different pore sizes are obtained. It is observed that despite a low porosity fraction (around $0.01 \%$ ), the influence of pores on the fatigue strength of the materials is pronounced. A mapping approach is presented, which links the applied stress, the pore size and the fatigue life. This approach makes it possible to accurately characterize the effect of the porosity size, and also to construct Kitagawa-Takahashi diagrams from S-N data.
\end{abstract}

\section{Introduction}

During recent years, additive manufacturing (AM) technologies have continued to grow steadily due to industrial and academic developments. One of the main advantages of this technology is the capacity to fabricate complex geometries directly from a computer-aided design. Among several metal AM processes, Selective Laser Melting (SLM) is one of the most commonly used. In this process, the energy of the laser source is used point-wise to melt powder within a powder-bed layer. Upon completion of a single layer, recoating of a new powder-layer is done and subsequent melting is pursued to continue the manufacturing process to build the 3D geometry. As for the material, the TA6V (Ti6Al4V) titanium alloy is one of the most common alloy manufactured by the SLM process and has applications in many industries, in particular the aeronautic and the medical domains. The mechanical properties of TA6V alloy obtained by this process have been intensively studied in the literature [1] [2] [3] [4] [5]. For the monotonic tensile behaviour, it has been observed that the tensile strength of the AM TA6V is equivalent or even higher than the alloys obtained by conventional processes [6] [7] [8]. However, in terms of fatigue behaviour, the AM TA6V alloy shows significantly lower fatigue strength [9] [10] [11]. This fact is due principally to microstructural defects in the AM materials, in particular porosity. The impact of pore size on the fatigue behaviour of the AM TA6V alloys has been investigated in the literature [12] [13] [14]. However, to the best of the authors' knowledge, the effects of pore at the surface or in the volume or the effect of the pore geometry are rarely mentioned.

The principal aim of this paper is to contribute to the understanding of the impact of porosity on the fatigue behaviour of the TA6V alloys obtained by the SLM process. In order to achieve this aim, a vast experimental fatigue campaign for uniaxial loading mode (loading ratio $\mathrm{R}=0.1$ ) has been undertaken. Five different specimen batches have been investigated. They were obtained using different AM building directions (horizontal, vertical and diagonal). All of the specimens were machined to avoid the effect of the as-built surface.

The fatigue behaviour and the associated fatigue crack initiation mechanisms are presented. The influence of porosity, including the effects of the surface/volume pores and of the pore geometry will be highlighted thanks to a mapping approach that links the applied stress, the pore size and the fatigue life. A first results of a fatigue model will also be discussed.

\section{Material and experimental conditions}

\subsection{Material and specimen fabrication}

The TA6V alloy used in this study is grade 5 ELI for which the referred chemical composition (source www.titane-services.fr) is shown in Table 1.

The specimen were fabricated by IRT Jules Verne by using a SLM®280 HL machine. The fabrication process has been optimized thanks to a vast experimental campaign in which several process parameters such as laser power, scan speed, hatch distance or focus were 
taken into consideration. Note that the process parameters were the same for all of the specimen batches investigated in the present work.

Table 1. Referred chemical compositions of the investigated TA6V alloy

\begin{tabular}{|c|c|c|c|c|c|c|}
\hline $\mathrm{Al}$ & $\mathrm{V}$ & $\mathrm{C}$ & $\mathrm{Fe}$ & $\mathrm{H}$ & $\mathrm{N}$ & $\mathrm{O}$ \\
\hline 6.0 & 4.0 & $\leq 0.08$ & $\leq 0.25$ & $\leq 0.0125$ & $\leq 0.05$ & $\leq 0.13$ \\
\hline
\end{tabular}

For monotonic tensile tests, three specimen batches with 5 specimens per batch, referred to as $0^{\circ}, 45^{\circ}$ and $90^{\circ}$, corresponding to the building direction, were fabricated. Note that for the $0^{\circ}$ configuration, the specimen axis is perpendicular to the building direction. The tensile specimens have a plate shape with a gauge section of approximately $6 \times 2 \mathrm{~mm}^{2}$.

For the fatigue tests, five specimen batches are investigated in this study, referred to as $0^{\circ}-\mathrm{B} 1,0^{\circ}-\mathrm{B} 2$, $45^{\circ}-\mathrm{B} 1,45^{\circ}-\mathrm{B} 2,90^{\circ}$. Table 2 summaries the fabricated fatigue specimen batches. Fig. 1 shows the $0^{\circ}$ and $45^{\circ}$ fatigue specimen batches.

Table 2 : Summary of the fabricated fatigue specimen batches

\begin{tabular}{|c|c|c|c|}
\hline $\begin{array}{c}\text { Building } \\
\text { direction }\end{array}$ & $\begin{array}{c}\text { Specimen } \\
\text { surface }\end{array}$ & Batch Id & $\begin{array}{c}\text { Number of } \\
\text { specimens }\end{array}$ \\
\hline \multirow{2}{*}{$0^{\circ}$} & \multirow{2}{*}{ Machined } & $0^{\circ}-\mathrm{B} 1$ & 10 \\
\cline { 3 - 4 } & & $0^{\circ}-\mathrm{B} 2$ & 10 \\
\hline \multirow{2}{*}{$45^{\circ}$} & \multirow{2}{*}{ Machined } & $45^{\circ}-\mathrm{B} 1$ & 14 \\
\cline { 3 - 4 } & $45^{\circ}-\mathrm{B} 2$ & 6 \\
\hline $90^{\circ}$ & Machined & $90^{\circ}$ & 20 \\
\hline
\end{tabular}

After fabrication, all of the specimens were post heat treated by a usual heat treatment (annealed at 850 ${ }^{\circ} \mathrm{C}$ for 2 hours following by a slowly cooling within the furnace) to relax the residual stresses.

The machining of all specimens was done after the heat treatment. The $\mathrm{Ra}$ roughness of the machined surface is lower than 0.8 . The fatigue specimen geometry (shown in Fig. 2) is given as per the ISO 2072:2010 standard and is the same for all batches. The position of all of the fatigue specimens on the plate was registered in order to investigate the possible effect of the specimen position on the fatigue strength of the specimens.

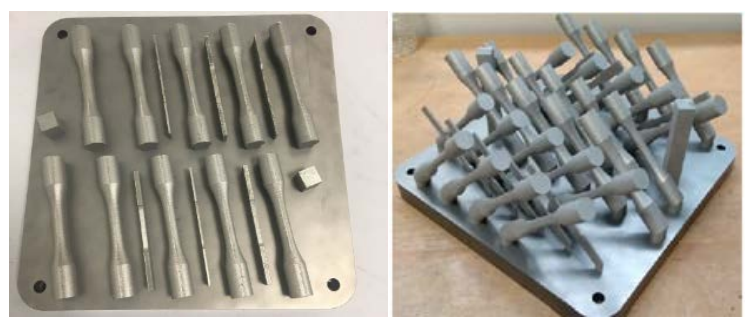

Fig. 1. (Left) $0^{\circ}-\mathrm{B} 1$ batch and (Right) $45^{\circ}$ batch

\subsection{Material and mechanical property characterization}

\subsubsection{Microstructure characterization}

The microstructure was observed using a light optical ZEISS microscope on polished and chemically etched samples (by using the Kroll solution for $20 \mathrm{~s}$ ). These samples were cut from the fatigue specimens after fatigue testing.

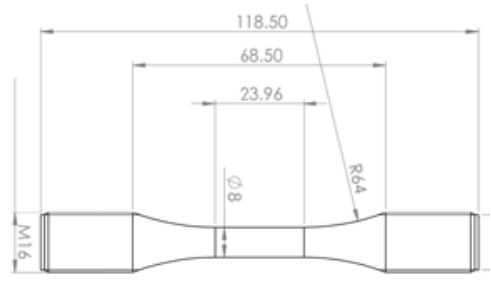

Fig. 2. Geometry for all of the fatigue specimens

\subsubsection{Monotonic tensile testing}

The monotonic tensile tests were done using an INSTRON servo-hydraulic machine. The strain was measured thanks to an extensometer with an initial length $\mathrm{L}_{0}=25 \mathrm{~mm}$ and a displacement range $\square \mathrm{L}=+/-2.5$ $\mathrm{mm}$. All of the tests were conducted with a constant strain rate of $0.005 \mathrm{~min}^{-1}$ at ambient temperature.

\subsubsection{Fatigue testing}

All of the fatigue tests presented below were carried out at ambient temperature and pressure in laboratory air. The fatigue tests were conducted with a constant stress amplitude with a loading ratio $\mathrm{R}=0.1$ at a frequency of $20 \mathrm{~Hz}$. A maximum fatigue life of $2 \times 10^{6}$ cycles was used. The stopping criterion was chosen to be the complete rupture of the specimen. The run-out specimens that survived $2 \times 10^{6}$ cycles were re-tested at a higher load. All of the fatigue failure surfaces were analysed on a ZEISS Gemini SEM.

\section{Results and discussion}

\subsection{Microstructure and porosity characterization}

It is well known in the literature that the microstructure of the TA6V alloys obtained by AM processes is columnar [15] with grains growing according to the building direction. In the present work, all of the specimens were fabricated and post-heat treated with the same parameters and heat treatment conditions. Therefore, the microstructures of all of the batches must be the same for all specimen orientations.

The microstructural characterization was realized on samples cut from the fatigue specimens after fatigue tests. The cut planes are perpendicular to the specimen axis in order to measure the pore size in the principal stress plane. It can be seen in Fig. 3. that the microstructure of the $0^{\circ}$ specimen is columnar but this is not the case for the $45^{\circ}$ and $90^{\circ}$ specimens. In fact, for the $0^{\circ}$ samples, the cut planes are parallel to the building direction. For $45^{\circ}$ and $90^{\circ}$ specimens, the observation planes are not parallel to the building direction. 


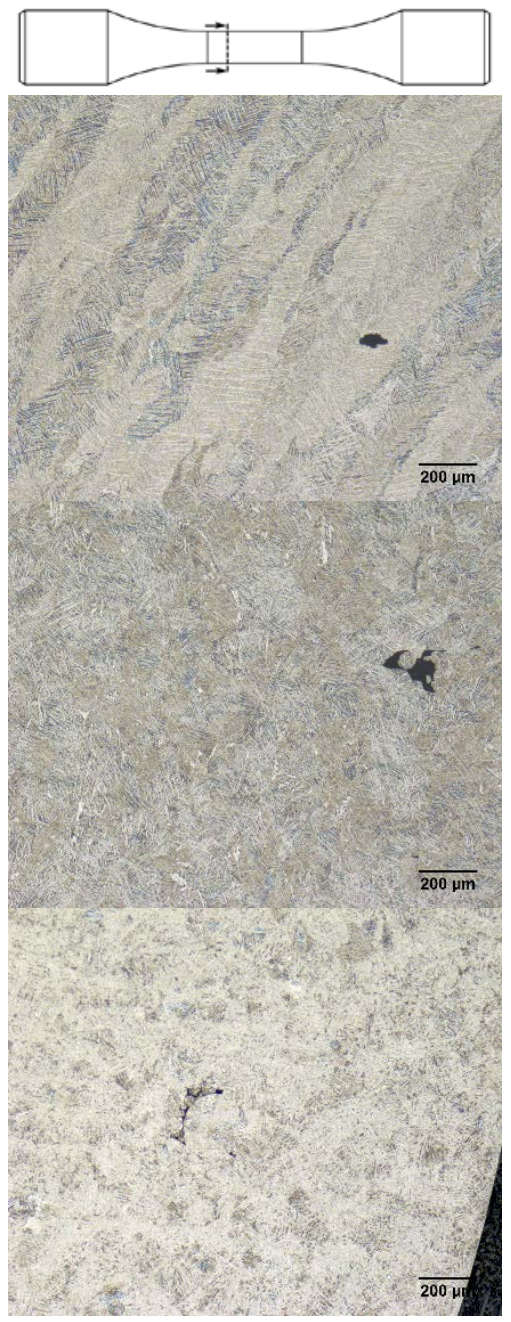

Fig. 3. Microstructures observed on polished samples from $0^{\circ}$-B1 batch (top), $45^{\circ}$-B1 batch (middle) and $90^{\circ}$-B1 batch (bottom). Observation planes are perpendicular to the specimen axis.

The porosity characterizations were conducted on 3 batches $0^{\circ}-\mathrm{B} 1,45^{\circ}-\mathrm{B} 1$ and $90^{\circ}$. The characterization methodology proposed by Murakami [16] was used. As per this method, the size of the biggest pore observed in each standard inspection area of size $\mathrm{S}_{0}$ is measured. The resulting distribution corresponds to the extreme value distribution related to the area $\mathrm{S}_{0}$. In the present work, the inspection area $S_{0}$ is equal to the area of the taken images, $\mathrm{S}_{0}=2.34 \mathrm{~mm}^{2}$. The $\sqrt{\text { area }}$ of pores is used to define the pore size. For each batch, 300 observations were realized from samples cut from 3 fatigue specimens after fatigue tests. The three specimens were intentionally chosen so that their fatigue strengths are representative of the fatigue strength of the batch.

It is worth noting that almost all images contain no more than one pore so the porosity can also be estimated. Table 3 shows the porosity density of the three investigated batches.

Table 3. porosity density (surface measurement) of the three batches $0^{\circ}-\mathrm{B} 1,45^{\circ}-\mathrm{B} 1$ and $90^{\circ}$

\begin{tabular}{|c|c|}
\hline Batch Id & Porosity (\%) \\
\hline $0^{\circ}-\mathrm{B} 1$ & 0.003 \\
\hline $45^{\circ}-\mathrm{B} 1$ & 0.013 \\
\hline $90^{\circ}$ & 0.004 \\
\hline
\end{tabular}

The pore size distributions for the three batches $0^{\circ}$ $\mathrm{B} 1,45^{\circ}-\mathrm{B} 1$ and $90^{\circ}$ are shown in Fig. 4. The y-axis is presented by using the reduced variable, $Y$, defined as a function of the cumulative probability, $F$, given as the following:

$$
Y=-\ln (-\ln F)
$$

It can be observed that the size of the pores observed for $0^{\circ}$-B 1 specimens are the smallest while the pore sizes for the $45^{\circ}-\mathrm{B} 1$ are the biggest.

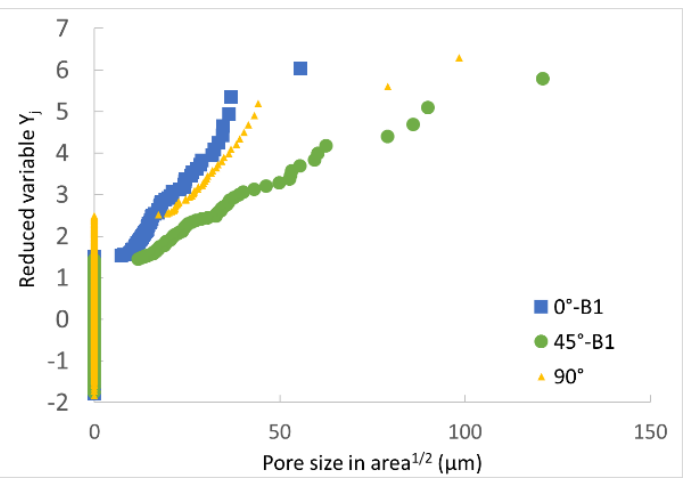

Fig. 4. Pore size distributions of the three batches $0^{\circ}-\mathrm{B} 1$, $45^{\circ}-\mathrm{B} 1$ and $90^{\circ}-\mathrm{B} 1$ observed on polished samples.

Finally, it is worth mentioning the anisotropy of the pore geometry. In the investigated alloys, it will be shown in the next section that the critical pores observed at the fatigue crack initiations are principally related to the lack of fusion. In the work of Kasperovich et al. [17], the authors showed, thanks to micro-tomography observations, that the pores relating to the lack of fusion have a very spread geometry, i.e. a large area but small thickness. The plane on which pores spread out is generally perpendicular to the building direction. Fig. 5 shows a pore observed by optical microscopy on a $0^{\circ}$ specimen.

Fig. 6 shows a schema illustrating the anisotropies of the microstructure and of the pores and also the orientation of the observation planes for specimens of 3 building directions.

One of the questions in this work is to know which parameter is more important to consider in fatigue between the particular microstructure and the porosity population.

\subsection{Monotonic tensile behaviour.}

The comparison of the ultimate tensile strength ( $\mathrm{Rm})$, the yield strength (Rp0.2) and the fracture strain of the six investigated batches is shown in Fig. 7. The error bars correspond to the standard deviations of the determined properties. 
It can be seen that the $45^{\circ}$ specimens show the greatest yield strength and ultimate tensile strength and the $90^{\circ}$ specimens have the lowest values.

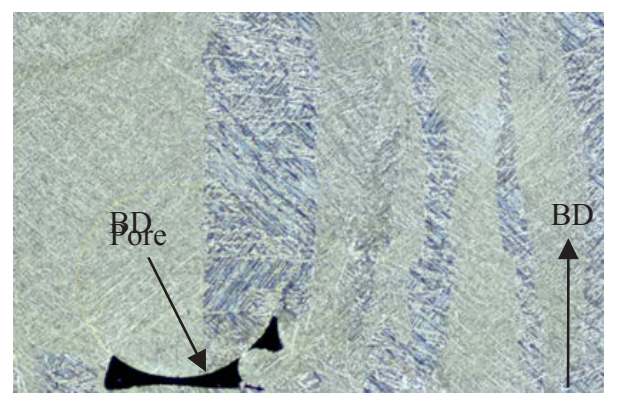

Fig. 5. A pore observed by optical microscopy on a $0^{\circ}$ specimen in the present project.

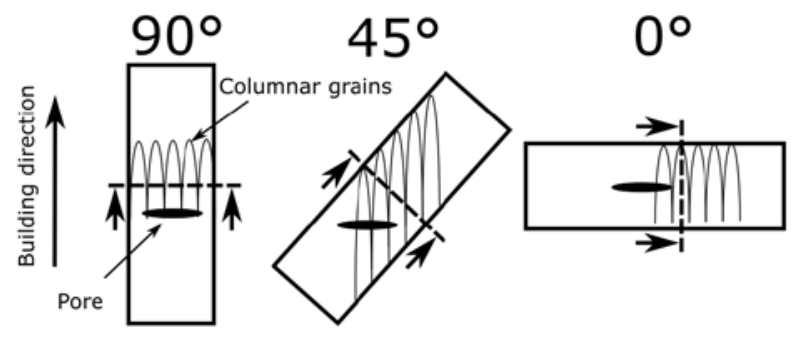

Fig. 6. Schema showing the orientation of pores and the observation planes (dashed lines) for $0^{\circ}, 45^{\circ}$ and $90^{\circ}$ specimens.

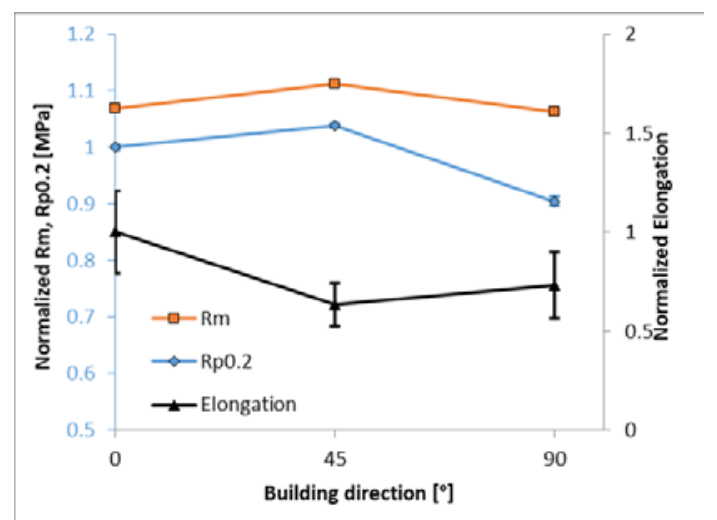

Fig. 7. Monotonic tensile properties for three investigated batches

\subsection{Fatigue behaviour and fatigue crack initiation mechanisms}

\subsubsection{S- $N$ curves}

Fig. 8 shows the S-N curves for the 5 investigated batches: the top figure for $0^{\circ}$ batches, the middle figure for $45^{\circ}$ batches and the bottom figure for $90^{\circ}$ batch. The regression lines correspond to the Stromeyer theoretical model [18] as given by the following equation.

$$
\log N=A-B \log \left(\Delta \sigma-\Delta \sigma_{0}\right)
$$

Firstly, a large difference can be seen between the two $0^{\circ}$ batches as well as between the two $45^{\circ}$ batches, in spite of the fact that the same process parameters were used. The measurements of the fabrication conditions such as the oxygen level or the plate and chamber temperatures also showed that there was no notable difference between batches. For the moment, the authors cannot explain why there is such differences. It is assumed that the fabrication repeatability was not obtained in the present work.

Another observation that can be made for the $0^{\circ}$ and $45^{\circ}$ batches is that the S-N data scatter is higher for the $0^{\circ}-\mathrm{B} 2$ and $45^{\circ}-\mathrm{B} 2$ batches for which the fatigue strengths are better. For the $90^{\circ}$ batch, it can be seen that the fatigue scatter is very high. It seems that there are two distinguished S-N curves: one for the 3 points indicated by the arrows and the other one is for the remaining 17 points. The Stromeyer curve shown was fitted to these 17 points.

The comparison of all of the specimen batches is shown in Fig. 9. It can be seen that generally, except the 3 points mentioned previously, the fatigue strength of the $90^{\circ}$ batch is the lowest. For the $0^{\circ}$ and $45^{\circ}$ specimens, the difference between the $0^{\circ}-\mathrm{B} 2$ and $45^{\circ}-\mathrm{B} 2$ is very slight. The difference between the $0^{\circ}-\mathrm{B} 1$ and $45^{\circ}-\mathrm{B} 1$ is also small in the high cycle number regime $\left(\mathrm{N}_{\mathrm{f}}>10^{5}\right.$ cycles) and more pronounced in the low cycle number regime.

It can also be seen that the higher fatigue strength of the $45^{\circ}-\mathrm{B} 1$ batch compared to the $90^{\circ}$ batch is not in agreement with the pore size distributions measured on polished samples of these batches. It was shown in Fig. 4. that the pore size of the $45^{\circ}$-B 1 specimens is larger than for the $90^{\circ}$ specimens. One possible explanation is that the pore size distributions measured on polished samples are not representative of the real material porosity for all of the building directions. As mentioned in section 3.1, the critical pores in the investigated alloys have a very spread geometry in the planes perpendicular to the building direction. The authors assume that for this reason, the probability that the observation planes contain the biggest pores is small for the $90^{\circ}$ samples despite a large number of observations (300 observations with an area $\mathrm{S}_{0}=2.34 \mathrm{~mm}^{2}$ were realized on 3 specimens). 


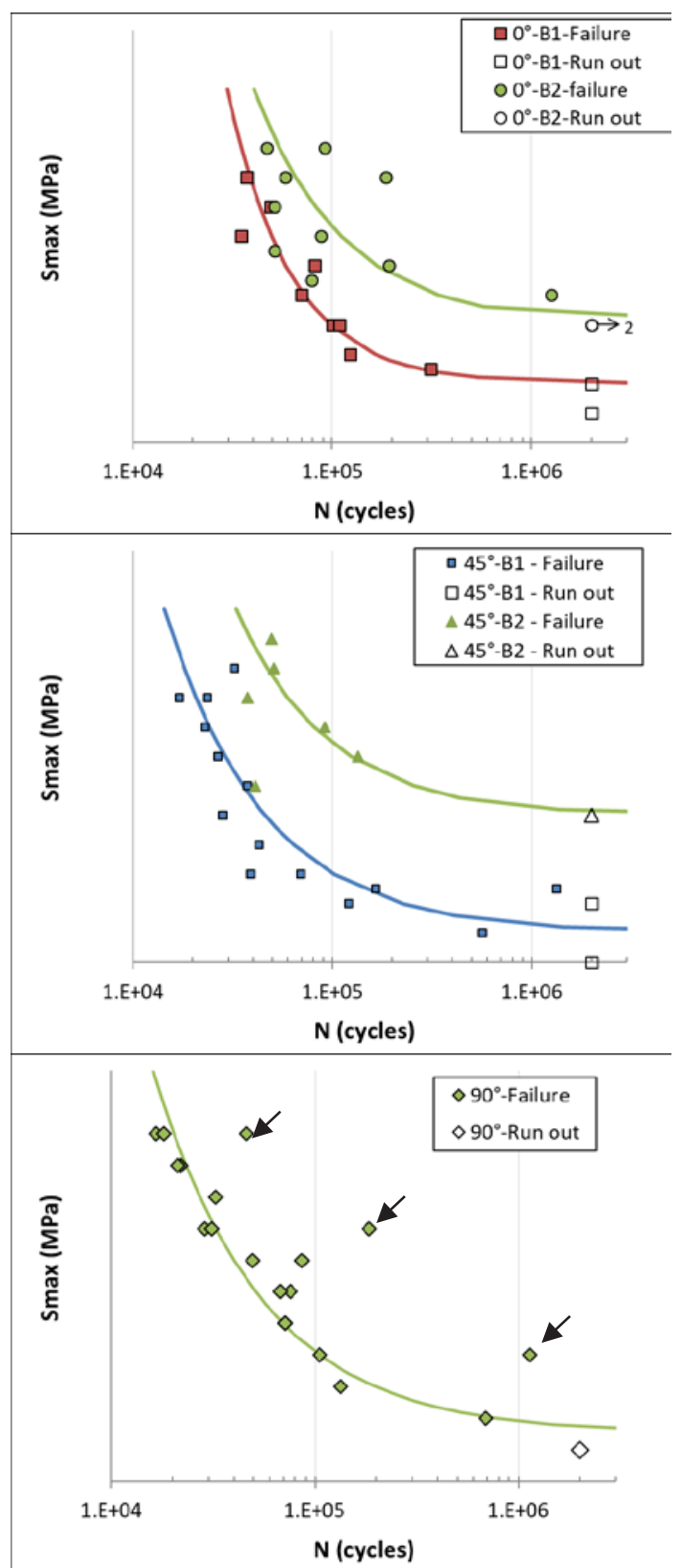

Fig. 8. Wöhler curves for all of specimen batches: $0^{\circ}$ batches (top); $45^{\circ}$ batches (middle) and $90^{\circ}$ batch (bottom)

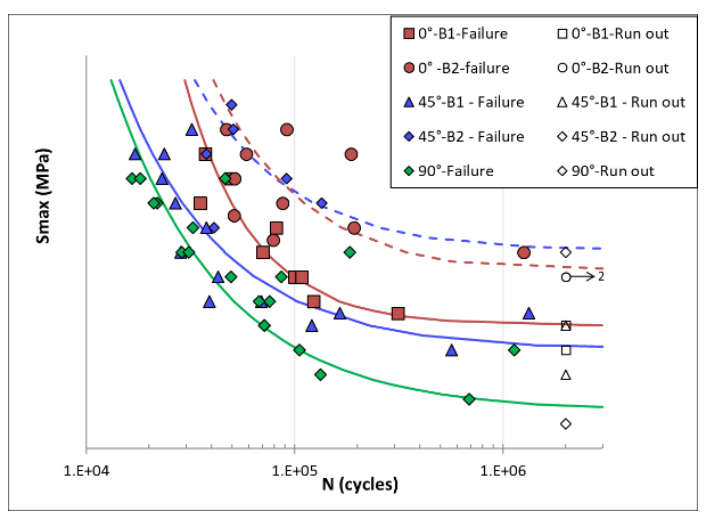

Fig. 9. Comparison of the Wöhler curve of all of the specimen batches

\subsubsection{Crack initiation mechanisms}

All of the fatigue cracks initiate from one site. Almost all the fatigue cracks initiate from a pore (observed on 59 specimens out of a total of 60). Among them, 4 cracks initiate from internal pores and the others initiate from surface pores. Only one specimen with crack initiation from the microstructure was observed. Fig. 10 shows crack initiations from surface pores observed on $0^{\circ}, 45^{\circ}$ and $90^{\circ}$ specimens.

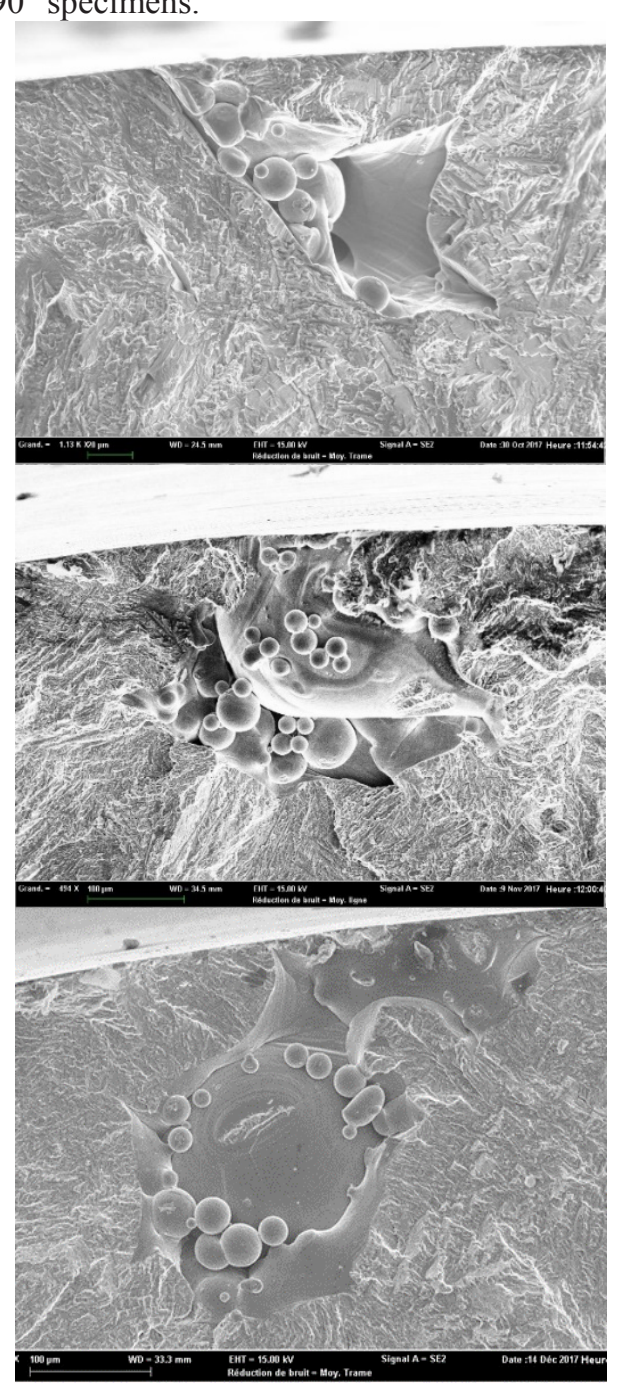

Fig. 10. A fatigue crack initiation from surface pore observed on a $0^{\circ}$ specimen (Top), $45^{\circ}$ specimen (Middle) and $90^{\circ}$ specimen (Bottom).

\subsection{Characterization of the effect of pore size on the fatigue behaviour}

All of the fatigue failure surfaces were analysed by using a SEM in order to measure the $\sqrt{\text { area }}$ of the pores at the crack initiation sites. Fig. 11 shows the comparison of the pore size distribution of all of the specimen batches. The normalized fatigue strengths, $\sigma_{\mathrm{D}, \mathrm{n}}$, estimated thanks to the Stromeyer fitting curves at a fatigue life of $2 \times 10^{6}$ cycles are also shown. It can be seen that the pore size distributions are generally in a good agreement with the fatigue strengths. In fact, it was shown that the $90^{\circ}$ 
specimens have the lowest fatigue life. The $0^{\circ}-\mathrm{B} 2$ and $45^{\circ}-\mathrm{B} 2$ showed a similar fatigue $\mathrm{S}-\mathrm{N}$ behaviour while the fatigue life of $0^{\circ}-\mathrm{B} 1$ batches is slightly higher than the $45^{\circ}-\mathrm{B} 1$ batch. Another observation could be made is that by comparing with the pore size distributions measured on polished samples for the three batches $0^{\circ}$ B1, $45^{\circ}-\mathrm{B} 1$ and $90^{\circ}$ (Fig. 4), the size of the pores at the crack initiation sites is much larger. Also, a disagreement can be seen: for the distributions measured on polished samples, the size of the pores of the $45^{\circ}-\mathrm{B} 1$ specimens are the largest however for the measurements on the crack initiation sites, the pore size of the $90^{\circ}$ specimens is the biggest. This disagreement was discussed in section 3.4.1.

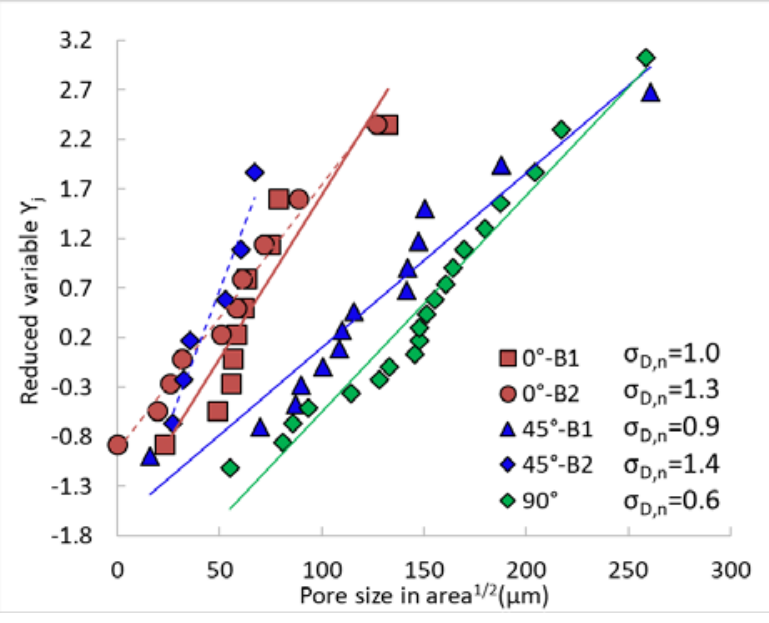

Fig. 11. Comparison of the pore size distributions measured on the crack initiation sites and the normalized fatigue strengths, $\sigma_{\mathrm{D}, \mathrm{n}}$, of the five investigated specimen batches.

Because of the large scatter related to the fatigue data as well as to the pore size distributions, the presentation of the pore size distributions is limited to a very coarse view of the effect of pore size. In order to better understand the pore size effect, a mapping that links the applied stress (S), the pore size measured at the crack initiation site $(\sqrt{\text { area }})$ and the fatigue life $\left(\mathrm{N}_{\mathrm{f}}\right)$ is used and shown in Fig. 12 for the three building directions. A linear interpolation in terms of $\log \left(\mathrm{N}_{\mathrm{f}}\right)$ was used to fill the maps. The Y-axis scale is the same for all of the three maps. The run-out specimens are also presented with a fatigue life of $2 \times 10^{6}$ cycles and with a pore size measured on the failure surface of the same specimen after re-tested at higher load.

Thanks to these diagrams, two interesting observations can be highlighted. Firstly, the arrows shown in the top and bottom maps of Fig. 12 (for the $0^{\circ}$ and the $90^{\circ}$ batches) indicate some "perturbation" points that show a better fatigue strength compared to others. The observations on the fatigue failure surfaces showed that these points correspond to the crack initiation from internal pore as shown in the top map of Fig. 13. Secondly, the arrows shown in the middle map of Fig. 12 indicate also three points with a slightly better fatigue life. These points relate to crack initiation from spherical gas pores (see Fig. 13-Bottom) that have a much more regular geometry than the pores associated with the lack of fusion or non-melted particles.

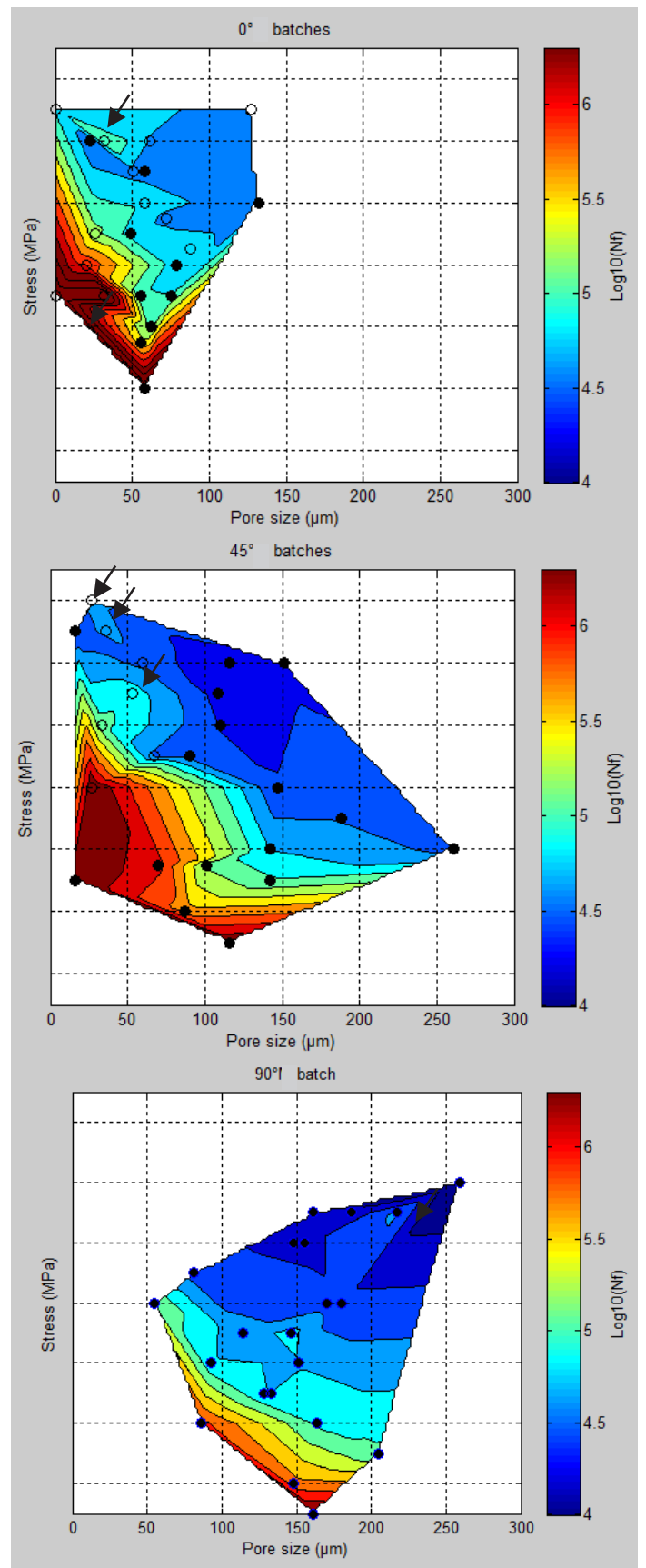

Fig. 12. $\mathrm{S}-\sqrt{\text { area }}-\mathrm{N}_{\mathrm{f}}$ mapping for the $0^{\circ}$ batches (top), $45^{\circ}$ batches (middle) and $90^{\circ}$ batch (bottom). For the $0^{\circ}$ and $45^{\circ}$ batches, the solid points correspond to the B1 batch and the open points for B2 batch.

The superposition of all of the fatigue data of the specimen batches without internal and spherical gas pores in Fig. 14 shows good agreement between the stress, the pore size and the fatigue life in spite of large scatter related to the S-N curves as well as to the pore size distributions.

The effect of the microstructure on the fatigue life does not seem pronounced in comparison with the pore size. As an example, two points enclosed by the white 
ellipse in Fig. 14 correspond two critical pores with a similar size and geometry. The fatigue life of the two specimens are close (67619 and 69350 cycles) despite one is a $45^{\circ}$ specimen and the other is a $90^{\circ}$ specimen.

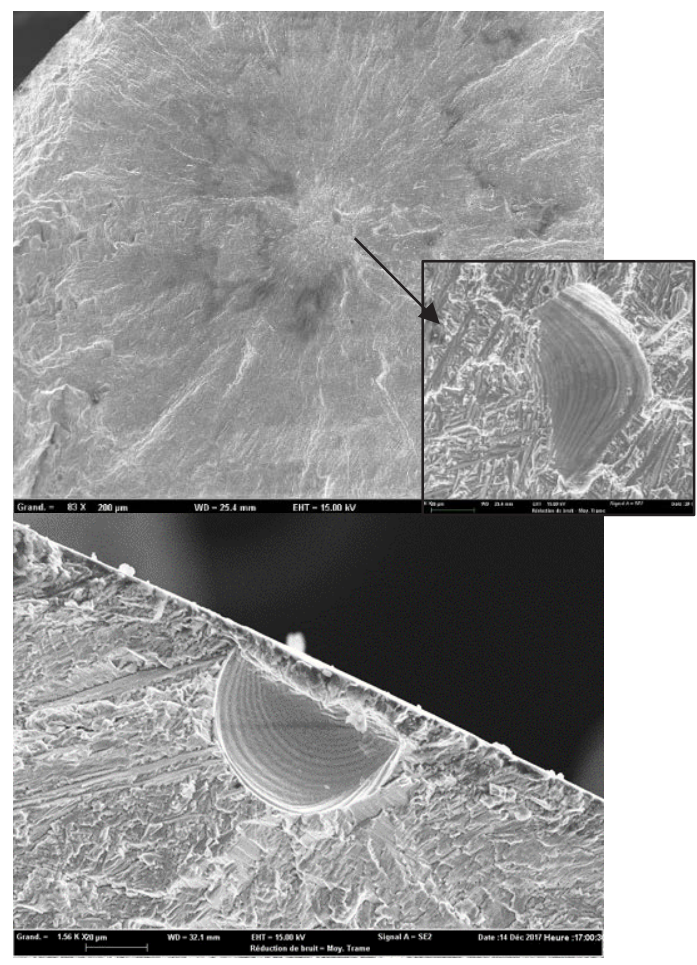

Fig. 13. Top - a fatigue crack initiation form an internal pore observed on a $0^{\circ}-\mathrm{B} 1$ specimen; Bottom - a fatigue crack initiation from a spherical gas pore observed on a $45^{\circ}$-B2 specimen

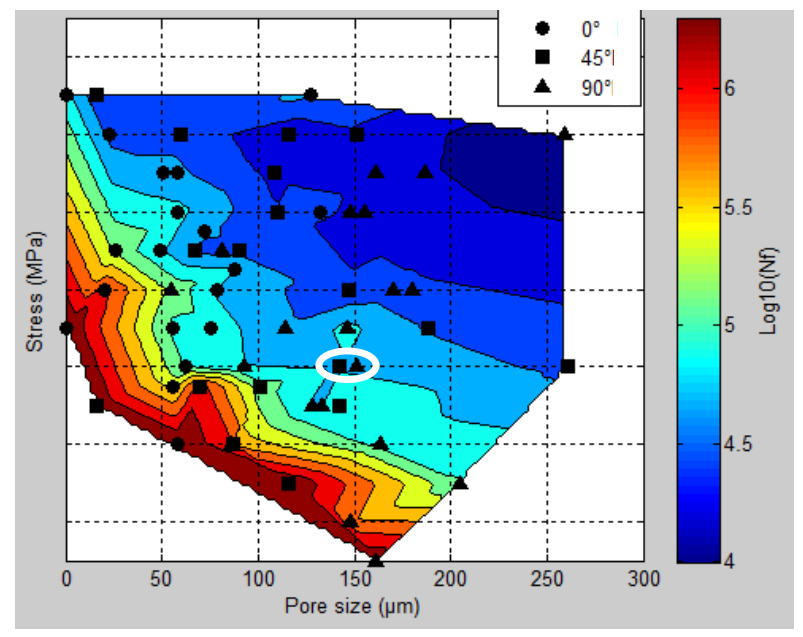

Fig. 14. $\mathrm{S}-\sqrt{\text { area }}-\mathrm{N}_{\mathrm{f}}$ mapping for all of the specimen batches (circle: $0^{\circ}$ batches, square: $45^{\circ}$ batches and triangle: $90^{\circ}$ ) with neither internal pores nor spherical gas pores.

Another advantage of this $\mathrm{S}-\sqrt{\text { area }}-\mathrm{N}_{\mathrm{f}}$ maps is that they can also be used as a pseudo-Kitagawa Takahashi diagram. If we assumed that the applied stress at a fatigue life of $2 \times 10^{6}$ cycles is the fatigue strength of the material, then the dark red region in these diagrams can be considered as the Kitagawa - Takahashi diagram. In order to estimate the trend of the KitagawaTakahashi diagram of the investigated alloy, three fatigue criteria, the classical linear elastic fracture mechanic, El-Haddad model and the Murakami approach, were used. The equations of the three criteria are given as follows.

- The classical LEFM criterion:

$$
\sigma_{D, a}=\frac{\Delta K_{t h}}{2 \times 0.65 \times \sqrt{\pi \sqrt{\text { area }}}}
$$

- El-Haddad approach:

$$
\sigma_{D, a}=\frac{\Delta K_{t h}}{2 \times 0.65 \times \sqrt{\pi(\sqrt{\text { area }}+\sqrt{\text { area }})}}
$$

where $\sqrt{\text { area }_{0}}=\frac{1}{\pi}\left(\frac{\Delta K_{t h}}{0.65 \times \Delta \sigma_{D 0}}\right)^{2}, \Delta \sigma_{D 0}$ is the fatigue strength of the porosity-free material.

- Murakami approach:

$$
\sigma_{D, a}=\frac{1.43(\mathrm{Hv}+120)}{\sqrt{\text { area }}^{1 / 6}} \times\left(\frac{1-R}{2}\right)^{\alpha}
$$

where $\alpha=0.226+\mathrm{Hv} \times 10^{-4}$

The material constants $\Delta K_{t h}$ and $\Delta \sigma_{D 0}$ were taken from the literature. The material hardness was experimentally measured on a $90^{\circ}$ sample (average value according to the sample height) and is supposed to be the same for all of the building directions. Fig. 15 shows on a log-log scale the three fatigue approaches and the experimental points for which the fatigue life is higher than $10^{5.5}$ cycles.

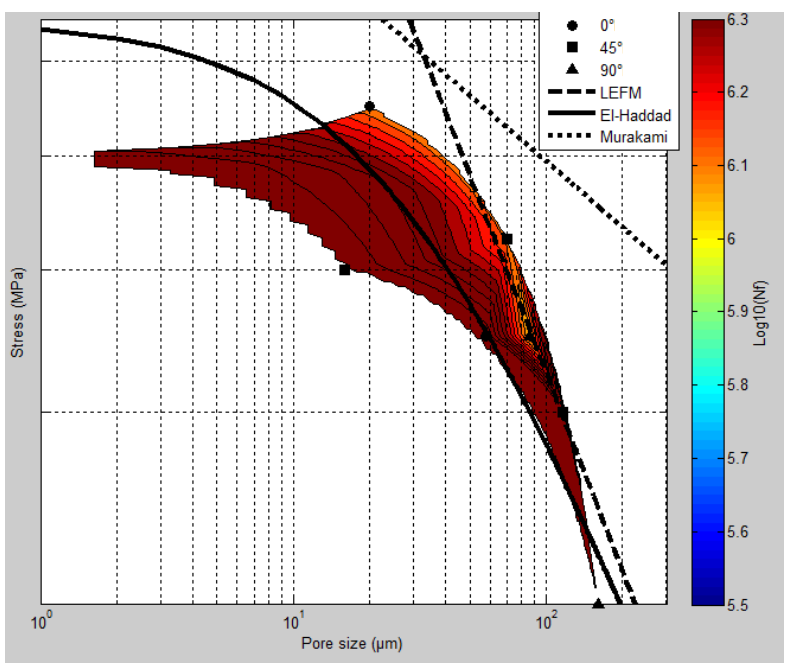

Fig. 15. $\mathrm{S}-\sqrt{\text { area }}-\mathrm{N}_{\mathrm{f}}$ mapping for specimens of which the fatigue life $\mathrm{N}_{\mathrm{f}}>10^{5.5}$ cycles. The dotted line relates to the Murakami approach, the dashed line corresponds to the classical LEFM fatigue criterion, the solid line for the ElHaddad model.

It can be seen that the El-Haddad model fits the experimental data better while the Murakami approach is very non-conservative. However, because of the limited 
number of experimental data, more fatigue tests in the high cycle fatigue regime need to be done.

\section{Conclusion}

In the present work, a vast experimental campaign was carried out to investigate the fatigue behaviour and the crack initiation mechanisms of the TA6V alloy obtained by the SLM process. Five fatigue specimen batches were fabricated with three building directions $\left(0^{\circ}, 45^{\circ}\right.$ and $\left.90^{\circ}\right)$. All of the specimens were machined in order to avoid the effect of the as-built surface. The microstructural and porosity characterizations showed high anisotropies in terms of microstructure and pore geometry. The pore size distributions were also measured by optical observations on polished samples for $0^{\circ}, 45^{\circ}$ and $90^{\circ}$ batches. It could be established a link between the pore size distribution and the fatigue strength for $0^{\circ}$ and $45^{\circ}$ batches. For the $90^{\circ}$ specimens the link seems not to be clear. The authors assumed that this is due to the high anisotropy of the pore geometry.

As for the fatigue behaviour, the $90^{\circ}$ batch showed the lowest fatigue life while the difference between $0^{\circ}$ and $45^{\circ}$ specimens is not pronounced. A large difference was also shown in terms of the fatigue behaviour between the two $0^{\circ}$ machined batches and between the two $45^{\circ}$ machined batches even though the same process parameters were used. Also, high scatter related to the S$\mathrm{N}$ curves was observed.

The characterization of the fatigue crack initiation mechanisms showed almost all of the fatigue cracks initiate from pores. In several observations, the pores associate with a large non-melted particle that could be formed by the balling effect.

The characterization of the pore size effect on the fatigue life was done thanks to a mapping approach that links the stress (S), the pore size ( Varea) and the fatigue life $\left(\mathrm{N}_{\mathrm{f}}\right)$. Good agreement between these three parameters is shown for all of the investigated batches despite the large scatter in terms of S-N data and pore size. It was also highlighted the beneficial effects of the distance to the specimen surface (i.e. internal vs surface pores) and the pore geometry (i.e. spherical gas pores). This mapping approach can also be used as a pseudo Kitagawa-Takahashi diagram. Three fatigue criteria, classical LEFM, El-Haddad and Murakami criteria, were applied to investigate the trend of pore size - fatigue strength relationship of the investigated alloy. Among them, the El-Haddad model best fits the experimental data.

Acknowledgement: This study is part of the FATAL project managed by IRT Jules Verne (French Institute in Research and Technology in Advanced Manufacturing Technologies for Composite, Metallic and Hybrid Structures). The authors wish to associate the industrial and academic partners of this project; Respectively ACB, Arts et Métiers ParisTech, CNRS, DAHER, Ecole Centrale de Nantes, Europe Technologies, FIVES, Renault and University of Nantes.

\section{References}

1. S. Leuders, T. Lieneke, S. Lammers, T. Tröster et T. Niendorf, J. Mater. Res. , vol. 29, pp. 1911-1919, 7 2014.

2. G. Kasperovich et J. Hausmann, J. Mater. Process. Technol. , vol. 220, pp. 202-214, 62015.

3. P. Edwards et M. Ramulu, Mater. Sci. Eng., A , vol. 598, pp. 327-337, 32014.

4. W. Xu, S. Sun, J. Elambasseril, Q. Liu, M. Brandt et M. Qian, JOM, vol. 67, pp. 668-673, 12015.

5. H. Gong, K. Rafi, H. Gu, G. D. J. Ram, T. Starr et B. Stucker, Mater. Des., vol. 86, pp. 545-554, 122015.

6. L. Bian, S. M. Thompson et N. Shamsaei, JOM, vol. 67, pp. 629-638, 22015.

7. H. K. Rafi, T. L. Starr et B. E. Stucker, The Int. J. Adv. Manuf. Technol. , vol. 69, pp. 1299-1309, 62013.

8. L. Facchini, E. Magalini, P. Robotti, A. Molinari, S. Höges et K. Wissenbach, RAPID PROTOTYPING J , vol. 16, pp. 450-459, 102010.

9. S. Leuders, S. Meiners, L. Wu, A. Taube, T. Tröster et T. Niendorf, J. Mater. Process. Technol., vol. 248, pp. 130-142, 2017.

10. A. Fatemi, R. Molaei, S. Sharifimehr, N. Phan et N. Shamsaei, Int. J. Fatigue, vol. 100, pp. 347-366, 7 2017.

11. A. Fatemi, R. Molaei, S. Sharifimehr, N. Shamsaei et N. Phan, Int. J. Fatigue, vol. 99, pp. 187-201, 62017.

12. J. Günther, D. Krewerth, T. Lippmann, S. Leuders, T. Tröster, A. Weidner, H. Biermann et T. Niendorf, Int. J. Fatigue, vol. 94, pp. 236-245, 12017.

13. D. Greitemeier, F. Palm, F. Syassen et T. Melz, Int. J. Fatigue, vol. 94, pp. 211-217, 12017.

14. S. Beretta et S. Romano, Int. J. Fatigue, vol. 94, pp. 178-191, 12017.

15. L. Thijs, F. Verhaeghe, T. Craeghs, J. V. Humbeeck et J.-P. Kruth, Acta Mater., vol. 58, pp. 33033312, 52010.

16. Y. Murakami, Elsevier, 2002.

17. G. Kasperovich, J. Haubrich, J. Gussone et G. Requena, Mater. Des. , vol. 105, pp. 160-170, 92016.

18. C. E. Stromeyer, Proceedings of the Royal Society of London A: Mathematical, Physical and Engineering Sciences, vol. 90, pp. 411-425, 1914.

19. K. S. Chan, M. Koike, R. L. Mason et T. Okabe, Metall. Mater. Trans. A, vol. 44, pp. 1010-1022, 10 2012.

20. R. Li, J. Liu, Y. Shi, L. Wang et W. Jiang, Int. J. Adv. Manuf. Technol. , vol. 59, pp. 1025-1035, 82011.

21. R. Konecna, G. Nicoletto, S. Fintova et M. Frkan, Procedia Struct. Integrity, vol. 7, pp. 92-100, 2017.

22. M. Benedetti, E. Torresani, M. Leoni, V. Fontanari, M. Bandini, C. Pederzolli et C. Potrich, J. 
Mech. Behav. Biomed. Mater., vol. 71, pp. 295-306, 7 2017.

23. A. Townsend, N. Senin, L. Blunt, R. K. Leach et J. S. Taylor, Precis. Eng. , vol. 46, pp. 34-47, 102016.

24. I. Koutiri, E. Pessard, P. Peyre, O. Amlou et T. D. Terris, J. Mater. Process. Technol. , vol. 255, pp. 536546, 2018. 